\title{
EDUKASI KESEHATAN DAN DETEKSI DINI HIPERTENSI, KOLESTEROL, ASAM URAT DAN DIABETES MELITUS DI GEREJA HKBP PPGS
}

\author{
Yenni Ferawati Sitanggang ${ }^{1}$, Deborah Siregar ${ }^{2}$, Veronica Paula ${ }^{3}$, Maria Yoche Maxmilla ${ }^{4}$, Dina \\ Valentina ${ }^{5}$ \\ $1,2,3,4,5$
}

Faculty of Nursing and Allied Health Science, University of Pelita Harapan, Jalan Siloam Hospital Karawaci, Tangerang, 15811, Indonesia

yenni.sitanggang@uph.edu, veronica.paula@uph.edu, deborah.siregar@uph.edu, dina.silaban@uph.edu

\begin{abstract}
Abstrak
Penyakit Tidak Menular (PTM) merupakan penyakit kronis yang tidak dapat ditularkan dari salah satu orang ke orang lainnya. WHO menunjukkan bahwa di seluruh dunia tercatat bahwa dari sejumlah 56.4 juta kematian yang terjadi pada tahun 2015 sekitar 39.5 juta (70\%) kematian disebabkan karena penyakit tidak menular (PTM). HKBP pos parmingguan Gading Serpong memiliki 120 jemaat yang terdiri dari anak-anak, remaja, dewasa dan lansia. Beberapa jemaat mengaku memiliki tekanan darah tinggi dan kadar gula darah yang tinggi dan jarang mengontrolkan dirinya ke tenaga kesehatan. Dua jemaat meninggal dunia akibat stroke. Disamping itu budaya Sumatera Utara yang terbiasa mengkonsumsi makanan asin dan berlemak dapat menjadi alasan kuat sebagai faktor resiko penyakit tersebut. Fakultas Keperawatan UPH pun melakukan kerjasama dengan seksi kesehatan HKBP pos parmingguan dalam hal meningkatkan status kesehatan jemaat. Dalam hal ini melakukan deteksi dini pemeriksaan gula darah, tekanan darah serta kolesterol dan melakukan edukasi kesehatan terkait penyakit tersebut guna meningkatkan pengetahuan jemaat dalam tindakan pencegahan terjadinya penyakit kronis. Hasil dari kegiatan ini adalah dari total 81 orang responden yang mengikuti edukasi kesehatan dan skrining kesehatan terdapat 31 orang mengalami tekanan darah yang tinggi yang dikategorikan sebagai hipertensi, 14 orang mengalami kolesterol, dan 6 orang mengalami gula darah yang tinggi (diabetes melitus). Dari hasil tersebut diharapkan bahwa promosi kesehatan yang dilakukan memberikan pemahaman yang baik dan perubahan sikap dari responden. Selanjutnya diharapkan juga agar setiap responden yang hadir menyadari pentingnya pencegahan penyakit kronis.
\end{abstract}

Kata Kunci: Deteksi Dini, Edukasi Kesehatan, Penyakit Tidak Menular 


\section{PENDAHULUAN}

Penyakit tidak menular (PTM) termasuk kedalam kategori penyakit kronis yang tidak ditularkan dari orang ke orang lain. Menurut Riskesdas 2013, yang termasuk kedalam kategori penyakit tidak menular antara lain asma, penyakit paru obstruktif, kanker, diabetes melitus, hipertiroid, hipertensi, jantung koroner, gagal jantung, gagal ginjal kronis, batu ginjal dan penyakit sendi atau rematik. Data secara global menurut World Health Organization (WHO, 2018) menunjukkan bahwa di seluruh dunia tercatat pada tahun 2015, dari 56.4 juta kematian terdapat sekitar 39.5 juta (70\%) kematian disebabkan oleh penyakit tidak menular (PTM). WHO menunjukkan data bahwa penyebab kematian utama di tahun 2015 adalah penyakit jantung sebanyak 17.7 juta (45\%), kanker sebanyak 8.8 juta (22\%), penyakit pernafasan (termasuk penyakit asma dan penyakit obstruktif kronis) sebanyak 3.9 juta dan diabetes melitus tercatat sebanyak 1.6 juta jiwa kematian.

Diabetes melitus merupakan penyakit yang diakibatkan karena pankreas tidak dapat memproduksi insulin yang cukup atau tubuh tidak dapat menggunakan insulin yang diproduksi dengan efektif (WHO, 2018). WHO menyebutkan bahwa di tahun 2014, sebanyak $8.5 \%$ dewasa usia 18 tahun dan lebih memiliki diabetes melitus. Selanjutnya di tahun 2015, diabetes melitus tercatat sebagai penyebab langsung kematian dari 1.6 juta orang di dunia (WHO,2018). Diabetes terbagi menjadi dua tipe yaitu Diabetes Melitus tipe 1 yang disebut sebagai Insulin Dependent Diabetes Mellitus (IDDM) dan Diabetes Melitus tipe 2 yaitu NonInsulin Dependent Diabetes Mellitus (NIDDM). Diabetes melitus memiliki gejala antara lain yaitu rasa haus yang berlebihan (polidipsi), sering kencing (polyuria) terutama di malam hari, sering lapar (polyphagia), berat badan menurun, kesemutan pada tangan dan kaki, gatal-gatal, penglihatan kabur, melahirkan bayi dengan berat badan lebih dari $4 \mathrm{~kg}$. Diabetes melitus tipe 1 disebabkan oleh keturunan dan faktor lingkungan, sedangkan diabetes mellitus tipe 2 disebabkan oleh gaya hidup yang meliputi kurang aktivitas, kelebihan berat badan atau obesitas (National Institute of Diabetes and Digestive \& Kidney Diseases, 2018). Hal ini diperkuat dalam studi oleh
Pilacinski \& Ziolkiewicz (2014) yang menjelaskan bahwa bahwa gaya hidup seperti kurang beraktivitas atau berolahraga, merokok, kebiasaan makan yang tidak sehat, stress dan gangguan pola tidur dapat meningkatkan resiko kejadian diabetes melitus pada orang dewasa.

Hipertensi adalah meningkatnya tekanan darah sistolik lebih dari $140 \mathrm{mmHg}$ dan tekanan darah diastolik lebih dari $90 \mathrm{mmHg}$ (Kemenkes RI, 2014). Data yang diperoleh bahwa sebanyak $25,8 \%$ orang yang mengalami hipertensi hanya $1 / 3$ yang terdiagnosis dan sisanya sebanyak $2 / 3$ tidak terdiagnosis. Selanjutnya dari $1 / 3$ yang terdiagnosis, hanya $0.7 \%$ orang yang meminum obat anti hipertensi (Kemenkes RI, 2016). Dari data yang tercatat membuktikan bahwa sebagian besar masyarakat Indonesia yang mengalami hipertensi belum menyadari pentingnya penanganan hipertensi dan pengobatannya. Hipertensi juga dapat menyebabkan komplikasi penyakit antara lain stroke, penyakit jantung koroner, diabetes melitus, gagal ginjal dan kebutaan jika tidak ditangani secara dini (National Heart, Lung and Blood Institute [NHIBI, 2018). Stroke dan penyakit jantung koroner dikatakan sebagai salah satu penyebab kematian tertinggi di Indonesia. Hussain et al. (2016) menyebutkan bahwa wanita memiliki resiko lebih tinggi terkena penyakit hipertensi dibandingkan pria selanjutnya dijelaskan juga bahwa kelebihan berat badan atau obesitas mempunyai hubungan yang bermakna terhadap angka kejadian hipertensi yang tidak terkontrol.

Hiperkolesterolemia atau biasa disebut dengan dislipidemia disebabkan karena metabolisme lipid karena adanya interaksi dari faktor genetik dan lingkungan terganggu (Perki, 2013). Hiperkolesterolemia juga merupakan penyakit kardiovaskular. Deteksi dini hiperkolesterolemia sendiri sering kali masih terbatas karena tingkat kesadaran masyarakat Indonesia untuk melakukan pemeriksaan hiperkolesterol pada kelompok masyarakat yang berisiko masih rendah. Berdasarkan hasil data yang didapatkan dari RISKESDAS tahun 2013 menunjukkan bahwa terdapat $35.9 \%$ dari jumlah penduduk Indonesia yang mempunyai usia $\geq 15$ tahun mempunyai kolesterol yang tidak normal (normal kadar kolesterol adalah $\geq 200 \mathrm{mg} / \mathrm{dl}$ ) dimana jumlah populasi perempuan yang lebih banyak mengalami

$$
\text { Kesehatan }
$$


hiperkolesterolemia dibandingkan laki-laki dan jumlah warga yang tinggal di kota lebih banyak yang terkena hiperkolesterolemia daripada penduduk di desa. Data RISKEDAS tahun 2013 juga menunjukkan bahwa terdapat $15.9 \%$ penduduk Indonesia yang berusia $\geq 15$ tahun mempunyai LDL yang sangat tinggi ( $\geq 190 \mathrm{mg} / \mathrm{dl}$ ), $22.9 \%$ penduduk Indonesia mempunyai HDL yang kurang dari $40 \mathrm{mg} / \mathrm{dl}$, dan $11.9 \%$ penduduk Indonesia dengan trigliserid yang tinggi $(\geq 500$ $\mathrm{mg} / \mathrm{dl}$ ). Hiperkolesterolemia adalah salah satu faktor terjadinya kejadian Penyakit Jantung Koroner (PJK) (Perki, 2015)

Gereja HKBP Pos Parmingguan memiliki jemaat kurang lebih sebanyak 190 orang yang memiliki usia beragam yang terdiri dari anak-anak, usia remaja, dewasa dan lansia. Permasalahan yang didapatkan oleh tim adalah bahwa didapatkan data ada beberapa jemaat gereja yang sudah terdiagnosa hipertensi serta diabetes, akan tetapi tidak terkontrol dan tidak melakukan pemeriksaan rutin karena merasa tidak mengalami keluhan. Menurut data yang didapatkan melalui wawancara kepada anggota jemaat, terdapat 2 jemaat yang meninggal dengan diagnosa medis CVDNH (Cerebrovaskular disease non haemorrhagic) atau stroke yang tidak disertai perdarahan. Kedua jemaat tersebut terlebih dahulu memiliki riwayat hipertensi yang tidak terkontrol. Selanjutnya, tim juga melakukan observasi dari beberapa jemaat baik dewasa maupun naposo (anak muda) yang memiliki berat badan yang termasuk dalam kategori kegemukan. Selain itu, kebiasaan gereja yang juga menyediakan makanan manis dan kopi atau teh setiap selesai ibadah dapat menjadi faktor resiko terjadinya penyakit tidak menular antara lain diabetes melitus, hipertensi, hiperkolesterolemia dan penyakit tidak menular lainnya.

Gaya hidup dapat menyebabkan resiko terjadinya hipertensi, diabetes mellitus, hiperkolesterolemia dan banyak penyakit lainnya. Pola gaya hidup yang dimaksud merupakan kebiasaan makan yang tidak tepat seperti memakan makanan yang berminyak, berlemak dan makanan yang asin bahkan terlalu manis serta tidak disertai dengan olahraga yang rutin (Kemenkes, 2016). Hal lain yang juga mendukung kebiasaan memakan makanan tersebut adalah budaya adat Sumatera Utara yang terbiasa memakan makanan asin, berminyak dan berlemak. Selain itu, kesibukan bekerja juga menjadi alasan kuat jemaat tidak melakukan aktivitas ataupun olah raga dan mengatakan tidak memiliki waktu banyak untuk melakukan olahraga. Hal ini yang menjadi permasalahan kesehatan jemaat HKBP pos parmingguan Gading Serpong. Saat ini ada dua dokter dan 3 jemaat yang memiliki latar belakang profesi sebagai perawat dalam HKBP pos parmingguan, kedua perawat tersebut merupakan staf keperawatan UPH. Selanjutnya, jemaat HKBP pos parmingguan belum pernah mendapatkan edukasi kesehatan tentang hipertensi dan diabetes melitus. Sehingga hal ini dianggap baik dalam kerjasama perawat dan dokter yang dapat dilakukan dalam bentuk skrining/ tes pemeriksaan hasil tekanan darah, gula darah dan kolesterol serta pelaksanaan edukasi kesehatan kepada Jemaat HKBP PPGS mengenai penyakit hipertensi dan diabetes melitus. Tujuan pelaksanaan kegiatan ini adalah diharapkan melalui kerjasama antara dokter dan perawat dapat meningkatkan pengetahuan jemaat akan pentingnya menjaga kesehatan dan melakukan pencegahan penyakit tidak menular.

\section{METODE}

Metode yang digunakan dalam kegiatan PkM ini adalah edukasi kesehatan dan pemeriksaan kesehatan yang diadakan adalah pemeriksaan tekanan darah, gula darah, asam urat dan kolesterol dan penyuluhan kesehatan pada dua topik besar yaitu hipertensi dan diabetes melitus. Kegiatan PKM ini dilakukan pada hari Sabtu, 21 Juli 2018 sesuai dengan kesepakatan yang telah diberikan. Tim melakukan konfirmasi kesiapan sebelum pelaksanaan kegiatan melalui telepon untuk memastikan bahwa semua undangan sudah disebarkan dan rencana kegiatan akan diumumkan saat ibadah minggu di gereja. Media serta peralatan yang digunakan dapat berfungsi dengan baik dan akurat. Proses pelaksanaan kegiatan baik edukasi kesehatan maupun skrining kesehatan berlangsung sangat tertib dan lancar. Setiap anggota tim kembali diberikan briefing tentang tugas dan tanggung jawab masing-masing. Sebelum pelaksanaan kegiatan dimulai, dilakukan ibadah oleh penatua PPGS dan sambutan oleh penatua, ketua tim kesehatan PPGS dan Ketua tim PkM. 
Hal yang pertama tim lakukan adalah dengan terlebih dahulu melakukan pengukuran tinggi badan dan berat badan sekaligus Indeks Massa Tubuh (IMT) yang dibantu oleh mahasiswa, lalu dilakukan skrining pemeriksaan tekanan darah, gula darah, asam urat dan kolesterol. Setelah masing-masing peserta diperiksa, tim memberikan lembar hasil pemeriksaan kepada masing-masing peserta. Hal ini dilakukan adalah agar setiap peserta mengetahui hasil dari masing-masing pemeriksaan sehingga bisa mengajukan pertanyaan yang berkaitan tentang hasil kesehatan mereka pada saat dilakukan penyuluhan kesehatan Diabetes Melitus dan Hipertensi. Pendidikan kesehatan merupakan perpaduan pengalaman dari belajar yang didesain untuk membantu masyarakat dan komunitas un tuk meningkatkan kesehatan mereka dengan meningkatkan kesehatannya melalui peningkatan tingkat pengetahuan dan memengaruhi sikapnya (WHO, 2018). Sehingga diharapkan dengan pelaksanaan edukasi kesehatan ini membantu setiap jemaat lebih memahami penyakit hipertensi dan diabetes melitus lebih lanjut dan mampu melakukan tindakan pencegahan penyakit. Tim menggunakan acuan klasifikasi tekanan darah dari Departemen Kesehatan tahun 2014. Pembagian tekanan darah dibagi menjadi normal, prehipertensi, hipertensi stage 1 dan hipertensi stage 2. Pembagian tekanan darah digambarkan seperti tabel di bawah ini.

Tabel 1 Klasifikasi Pengukuran Tekanan Darah

\begin{tabular}{|c|c|c|}
\hline $\begin{array}{c}\text { Tekanan } \\
\text { darah }\end{array}$ & $\begin{array}{c}\text { Tekanan } \\
\text { darah sistolik } \\
(\mathbf{m m H g})\end{array}$ & $\begin{array}{c}\text { Tekanan } \\
\text { darah } \\
\text { diastolic } \\
\text { (mmHg) }\end{array}$ \\
\hline Normal & $<120$ & $<80$ \\
\hline Pre Hipertensi & $120-139$ & $80-89$ \\
\hline $\begin{array}{c}\text { Hipertensi } \\
\text { stage 1 }\end{array}$ & $140-159$ & $90-99$ \\
\hline $\begin{array}{c}\text { Hipertensi } \\
\text { stage 2 }\end{array}$ & 160 atau $>160$ & 100 atau $>100$ \\
\hline
\end{tabular}

Tabel 2. Klasifikasi Pengukuran Kolesterol

\begin{tabular}{|c|c|}
\hline Kolesterol & Hasil \\
\hline Kolesterol & $<201 \mathrm{mg} / \mathrm{dL}$ \\
\hline Tidak Kolesterol & $\geq 200 \mathrm{mg} / \mathrm{dL}$ \\
\hline
\end{tabular}

Tabel 3. Klasifikasi Pengukuran Diabetes Melitus

\begin{tabular}{|c|c|}
\hline Diabetes Melitus & Hasil \\
\hline $\begin{array}{c}\text { Mengalami Diabetes } \\
\text { Melitus }\end{array}$ & $<180 \mathrm{mg} / \mathrm{dL}$ \\
\hline Tidak Diabetes Melitus & $>180 \mathrm{mg} / \mathrm{dL}$ \\
\hline
\end{tabular}

Selanjutnya tim mengarahkan peserta mengikuti penyuluhan kesehatan yang disampaikan dari kedua narasumber dengan latar belakang perawat dan dokter. Tim narasumber memberikan edukasi kesehatan tentang hipertensi dan diabetes mellitus dengan menggunakan media power point. Materi yang disampaikan oleh narasumber adalah penjelasan singkat tentang definisi, penyebab, tanda gejala serta penanganan dari kedua penyakit yaitu hipertensi dan diabetes mellitus. Tim juga memberikan edukasi tentang pengaturan gizi, cara pencegahan dan penanganan saat darurat dari kedua penyakit tersebut.

Saat pelaksanaan edukasi kesehatan, terlihat peserta sangat antusias mengikuti kegiatan tersebut. Peserta mengajukan pertanyaan baik mengenai materi diabetes melitus maupun hipertensi. Peserta juga menanyakan tentang diet atau pengaturan makan yang baik bagi penderita diabetes dan hipertensi. Pada saat evaluasi akhir, tim tidak memberikan pre test dan post test akan tetapi tim mengajukan pertanyaan verbal yang ditujukan secara umum kepada seluruh peserta. Tiga pertanyaan yang diajukan oleh tim terkait materi dapat dijawab oleh beberapa peserta dengan baik dan benar.

\section{HASIL DAN PEMBAHASAN}

Peserta yang hadir dalam edukasi kesehatan dan pemeriksaan kesehatan adalah sejumlah 81 orang. Dari sejumlah peserta yang hadir terdapat peserta wanita sebanyak 35 orang dan peserta pria 46 orang. Peserta hadir 30 menit sebelum pemeriksaan dimulai. Peserta terlihat sangat antusias mengikuti seluruh kegiatan terkait karena mengakutidak pernah mengikuti kegiatan serupa sebelumnya. Beberapa jemaat meminta agar kegiatan Pendidikan Kesehatan dan Pemeriksaan Kesehatan agar dapat dilaksanakan secara rutin karna sangat bermanfaat untuk setiap orang. Banyak dari jemaat yang hadir 
tidak pernah memeriksakan kesehatan mereka sendiri ke klinik atau rumah sakit karena alasan takut jika hasil tidak sesuai harapan. Selain itu jika tidak mengalami keluhan maka menurut peserta tidak ada gunanya memeriksakan diri untuk ke sarana pelayanan kesehatan. Pada saat pelaksanaan skrining di PPGS, beberapa jemaat mengaku lebih rileks saat dilakukan pemeriksaan karena tidak seperti di rumah sakit yang dirasa menegangkan dan menakutkan. Jemaat menyatakan bahwa kegiatan ini sangat bermanfaat dan sangat efektif.

Penyebab atau faktor resiko terjadinya hipertensi disebabkan oleh kurangnya aktivitas, penggunaan alcohol, merokok, obesitas, kolesterol dan diabetes mellitus (WHO, 2018). Dari seluruh peserta terdapat 39 orang peserta yang memiliki kebiasaan merokok setiap harinya sebanyak satu bungkus atau bahkan lebih. Hal ini dapat menjadi penyebab terjadinya peningkatan tekanan darah pada peserta diikuti juga dengan kebiasaan yang tidak mau berolahraga. WHO (2018) menyebutkan bahwa tekanan darah yang melebihi dimana tekanan systolic $>140 \mathrm{mmHg}$ dan tekanan diastolik $>90 \mathrm{mmH}$ disebut sebagai tekanan darah tinggi. Selanjutnya WHO (2018) juga menyebutkan bahwa kebanyakan dari orang-orang yang menderita hipertensi tidak merasakan gejala, sehingga seringkali penyakit hipertensi disebut sebagai penyakit silent killer.

Tabel 4 Hasil Pemeriksaan Tekanan Darah di PPGS (n=81)

\begin{tabular}{|l|c|c|}
\hline \multicolumn{1}{|c|}{ Kategori } & $\begin{array}{c}\text { Jumlah } \\
\text { Peserta }\end{array}$ & $\begin{array}{c}\text { Persentase } \\
(\mathbf{\%})\end{array}$ \\
\hline Normal & 50 & 61.72 \\
Pre hipertensi & 20 & 24.70 \\
Hipertensi Tahap 1 & 7 & 8.65 \\
Hipertensi Tahap 2 & 4 & 4.93 \\
Jumlah & 81 & 100 \\
\hline
\end{tabular}

Dari keseluruhan peserta yang hadir, didapatkan data bahwa lebih dari $60 \%$ peserta masih memiliki tekanan darah yang termasuk dalam rentang normal yaitu sebanyak 50 peserta (61.72\%), 20 orang mengalami pre hipertensi, tujuh (7) orang mengalami hipertensi tahap satu, empat (4) orang mengalami hipertensi tahap 2 (Tabel 4). Hal ini menunjukkan bahwa 31 orang peserta tersebut termasuk dalam kategori pre hipertensi, hipertensi stage 1, hipertensi stage 2 termasuk kedalam klasifikasi tekanan darah meningkat dari rentang normal dan beresiko mendapatkan komplikasi jika tidak ditangani dalam jangka panjang. Dengan mengetahui hasil pengukuran tekanan darah tersebut diharapkan jemaat Gereja HKBP Pos Parmingguan dapat melakukan tindakan preventif dan penatalaksanaan dengan memodifikasi diet makanan,gaya hidup maupun obat-obatan sehingga komplikasi akibat hipertensi dapat dihindarkan seperti stroke, serangan jantung, gagal jantung, dan gagal ginjal (Kemenkes RI, 2014).

Tabel 5 Hasil Pemeriksaan Kolesterol di PPGS $(\mathrm{n}=81)$

\begin{tabular}{|l|c|c|}
\hline Kategori & $\begin{array}{c}\text { Jumlah } \\
\text { Peserta }\end{array}$ & $\begin{array}{c}\text { Persentase } \\
(\boldsymbol{\%})\end{array}$ \\
\hline Kolesterol & 14 & 17.29 \\
Tidak & 67 & 82.71 \\
Jumlah & 81 & 100 \\
\hline
\end{tabular}

Berdasarkan data yang didapatkan, mayoritas peserta yang tidak memiliki kolesterol tinggi diatas $200 \mathrm{mg} / \mathrm{dl}$ adalah sebanyak 67 peserta $(82.71 \%)$. Akan tetapi, terdapat 14 peserta (17.29\%) yang menunjukkan hasil kolesterol di atas rentang normal yaitu dibawah $200 \mathrm{mg} / \mathrm{dl}$ (Tabel 5). Beberapa faktor yang dapat mempengaruhi peningkatan kolesterol dalam darah adalah makanan dan kurang beraktivitas atau berolahraga. Terbukti dari peserta yang hadir ada beberapa peserta yang kurang berolahraga. Sehingga langkah yang dilakukan untuk mengendalikan kolesterol dalam darah adalah pemberian edukasi mengenai pengendalian kadar kolesterol dan olahraga. Berdasarkan penelitian Zuhroiyyah, Sukandar, Sastradimaja (2017) pada masyarakat Jatinangor didapatkan data bahwa aktivitas fisik memiliki hubungan yang bermakna dengan kadar kolesterol. Hasil dari penelitian ini juga sejalan dengan teori yang mengatakan bahwa ketika kita melakukan aktivitas fisik atau olah raga, tubuh akan melakukan pembentukan energi berupa adenosin triphosphate (ATP) dari makanan yang dikonsumsi sehingga makanan yang dikonsumsi tidak banyak dibentuk menjadi kolesterol, akibatnya kadar kolesterol total di dalam tubuh menurun. 
Tabel 6 Hasil Pemeriksaan Diabetes Mellitus di PPGS (n=81)

\begin{tabular}{|l|c|c|}
\hline \multicolumn{1}{|c|}{ Kategori } & $\begin{array}{c}\text { Jumlah } \\
\text { Peserta }\end{array}$ & $\begin{array}{c}\text { Persentase } \\
(\mathbf{\%})\end{array}$ \\
\hline Diabetes Mellitus & 6 & 7.40 \\
Tidak & 75 & 92.60 \\
Jumlah & 81 & 100 \\
\hline
\end{tabular}

Berdasarkan data yang didapatkan ada enam orang $(7.40 \%)$ yang memiliki kadar gula darah lebih dari $180 \mathrm{mg} / \mathrm{dL}$. Sedangkan sebanyak 75 peserta $(92.60 \%)$ memiliki gula darah dalam rentang normal (Tabel 6). Walaupun peserta yang memiliki hasil gula darah tinggi tergolong sedikit, hal ini bisa menjadi pengingat buat peserta untuk menjaga pola makan dan gaya hidupn sehat karena diabetes melitus dapat terjadi dari waktu ke waktu dan tidak memandang usia dan dapat menyebabkan kerusakan di berbagai sistem tubuh terutama syaraf dan pembuluh darah.

\section{KESIMPULAN}

Seluruh rangkaian kegiatan edukasi kesehatan serta pemeriksaan kesehatan hipertensi, kolesterol, asam urat dan diabetes melitus berjalan dengan lancar, baik dan sesuai dengan yang direncanakan. Jemaat terlihat sangat antusias dan menyambut baik kedua kegiatan ini. Jemaat menyampaikan harapan agar kiranya dimasa mendatang dapat kembali bekerjasama dalam pengadaan rutin edukasi kesehatan dan pemeriksaan kesehatan yang dapat dilakukan bukan hanya di PPGS tapi bisa menjangkau masyarakat sekitar PPGS sehingga mendapat pengetahuan serta manfaat dan setiap masyarakat mampu meningkatkan derajat kesehatan mereka.

Setelah dilakukan kegiatan edukasi kesehatan serta skrining hipertensi, kolesterol, asam urat dan diabetes mellitus diharapkan jemaat PPGS dapat melakukan tindakan pencegahan seperti mengurangi rokok dan rutin melakukan aktivitas fisik karena tingginya morbiditas penyakit tersebut maka upaya pencegahan merupakan prioritas. Sering kita mendengar banyak orang mengatakan bahwa penyakit akan lebih mudah sembuh apabila penyakit diketahui lebih dini, tetapi kadang-kadang gejala awal dari suatu penyakit tidak dapat dirasakan oleh kita atau tidak terlihat oleh kita. Inilah pentingnya untuk melakukan pemeriksaan kesehatan secara berkala dan melakukan kebiasaan Cerdik cegah penyakit tidak menular antara lain dengan memeriksakan tekanan darah, penegcekan gula darah, Mengukur lingkar perut secara rutin dan Pengecekan kolesterol total.

\section{UCAPAN TERIMA KASIH}

Terima kasih kepada Lembaga Penelitian dan Pengabdian Masyarakat (LPPM) UPH atas dukungan dan review yang dilakukan dimulai dari pembuatan proposal sampai dengan pembuatan laporan akhir kegiatan ini. Nomor kegiatan ini adalah 233/LPPM-UPH/VI/2018. Selanjutnya tim mengucapkan terima kasih sebesar-besarnya pada Universitas Pelita Harapan (UPH) yang telah menyetujui kegiatan terkait dan memberikan bantuan dana untuk kelangsungan kegiatan tersebut. Akhir kata, ucapan terima kasih kami tujukan kepada tim kesehatan gereja HKBP PPGS dan penetua gereja yang mengijinkan dan mendukung pelaksanaan kegiatan edukasi kesehatan dan pemeriksaan gigi pada anak sekolah minggu HKBP PPGS.

\section{REFERENSI}

Infodatin, pusat data da informasi kementerian kesehatan RI, Hipertensi (2014) diakses dari http://www.depkes.go.id/download.php?file=downl oad/pusdatin/infodatin/infodatin-hipertensi.pdf

World Health Organization [WHO]. (2018). Diabetes. diakses pada http://www.who.int/mediacentre/factsheets/fs3 $\underline{12 / \mathrm{en} /}$

World Health Organization [WHO]. (2018). Health Education. (diakses dari http://www.who.int/topics/health education/en I

Hussain, M.A., Mamun, A.A., Reid, C \& Huxley, R.R. (2016). Prevalence, Awareness, Treatment and Control of Hypertension in Indonesian Adults Aged >40 Years: Findings from the 
Indonesia Family Life Survey (IFLS). PLOS

One. doi:10.1371/journal.pone.0160922

Kemenkes RI. 2014. Hipertensi. Jakarta: Pusat Data dan Informasi Kementerian Kesehatan Rl

Kemenkes RI. 2016. Rajin Cek Kesehatan, Kebiasaan Cerdik Cegah Penyakit Tidak Menular.

http://www.depkes.go.id/development/site/ depkes/index.php?cid=1$16100600008 \&$ id=rajin-cek-kesehatankebiasaan-cerdik-cegak-penyakit-tidakmenular

Perki (Perkumpulan Endokrinologi Indonesia). (2015). Panduan Pengendalian Dislipidemia di Indonesia 2015. Jakarta: PB Perkeni https://pbperkeni.or.id/wp-
content/uploads/2019/01/3.-PanduanPengelolaan-Dislipidemia-PERKENI-2015.pdf

Perki (Perkumpulan Endokrinologi Indonesia). (2013). Pedoman Tatalaksana Dislipidemia.. Jakarta: Centra Communications. http://www.inaheart.org/upload/file/Pedoman_t atalksana Dislipidemia.pdf

Piłaciński, S., \& Zozulińska-Ziółkiewicz, D. A. (2014). Influence of lifestyle on the course of type 1 diabetes mellitus. Archives of Medical Science: $\quad A M S, 10(1), \quad 124-134$. http://doi.org/10.5114/aoms.2014.40739

National Heart, Lung and Blood Institute [NHIBI]. (2018). Blood pressure. Diakses dari https://www.nhlbi.nih.gov/health-topics/highblood-pressure 